\title{
POR UMA EPISTEME DIALÓGICA, SENSÍVEL E CRIATIVA: UMA HOMENAGEM A ANA CLARA TORRES RIBEIRO
}

\section{Proposing a Dialogical Sensitive and Creative Episteme: a Tribute to Ana Clara Torres Ribeiro}

\author{
Anita Loureiro de Oliveira \\ Professora e coordenadora do curso de Geografia da UFRRJ \\ Tutora do grupo PET-Geografia e bolsista PET-MEC/SESu \\ anitaloureiro@yahoo.com.br
}

Artigo recebido em 13/06/2012 e aceito para publicação em 20/09/2012

RESUMO Este artigo pretende ser uma homenagem à Professora Ana Clara Torres Ribeiro e ao mesmo tempo uma reunião de algumas das contribuições de seu pensamento para a consolidação de uma episteme dialógica, sensível e criativa. Trata-se de uma geografia que reconhece no homem lento (SANTOS, 1997), ordinário (CERTEAU, 2003), o sujeito corporificado (RIBEIRO, 2005c) revelador de uma geografia da existência (RIBEIRO, SILVA \& SCHIPPER, 2011). Tal proposta sugere um transformador diálogo entre arte, ciência e política, fundamental à formação do sujeito.

Palavras-chave: Diálogo, Lugar, Contra-racionalidades

ABSTRACT This paper is in honour of Professor Ana Clara Torres Ribeiro and includes some of her thoughts to consolidate a dialogical sensitive and creative episteme. It's a Geography which acknowledges the embodied subject (RIBEIRO, 2005c) in the slow (Santos, 1997) and ordinary (Certeau, 2003) human beings that reveals a Geography of existence (RIBEIRO, \& SCHIPPER SILVA, 2011). This idea suggests an interchangeable dialogue between art, science and politics, fundamental to the formation of the subject.

Keywords: dialog, place, alternative rationality 
Ana Clara além de mestra era uma maestra, uma regente corporificada. Nunca deixou de fazer música. Formada pelo Conservatório Brasileiro em harmonia, contraponto e composição, ela nunca deixou de compor. Compunha com conceitos, ideias e palavras. Compunha textos, aulas e palestras. Compunha com a sociologia, a geografia e o urbanismo. Compunha com os ritmos, temas e melodias da experiência urbana. E, além de compor, ela regia corporalmente, como sua própria forma de ação no mundo. Uma grande maestra mestre, mestre na compreensão das micro-conjunturas, mestre na escuta do outro, maestra da experiência da alteridade. Regia a fala do Outro, dos tantos outros, mas ao invés de partituras, ela tecia cartografias. Cartografias das escutas do Outro, das resistências e das insurgências. Cartografias das ações, da vida coletiva e da vida vivida (Paola B. Jacques, 2010) $)^{1}$

Ana Clara Torres Ribeiro foi uma orientadora generosa, cuja sabedoria nos incentivava a viver (e refletir sobre) a vida, com criatividade, sensibilidade e respeito ao Outro. Depois de ter sido orientada por ela na elaboração de uma Tese de Doutorado intitulada Musica e Vida Urbana: encontros e confrontos na cidade do Rio de Janeiro (OLIVEIRA, 2008), gostaria muito de ter sido eu a autora da bela homenagem feita por Paola Jacques, mas me contento de poder citá-la na epígrafe acima.

Dentre tantas homenagens enviadas por alunos, ex-orientandos, pesquisadores, professores e tantos outros amigos e colegas de caminhada, algumas mensagens são dignas de citação, ao falarem da pessoa Ana Clara, da "delicadeza de seus gestos e palavras", "suas sonoras risadas, sua polidez, sua sensibilidade e inquietude", uma educadora comprometida com a formação do analista, do pesquisador, com sua "maneira muito especial de transformar dificuldades em algo pequeno, enxergando além das limitações, acreditando no potencial e respeitando o tempo de amadurecimento de cada um" ${ }^{2}$. Nenhum de nós vai "esquecer suas dicas humoradas e várias de suas expressões que nos animavam a seguir sempre em frente" baseando-se no seu exemplo de dedicação e ética ${ }^{3}$. 
Este artigo pretende ser uma homenagem à Professora Ana Clara Torres Ribeiro e ao mesmo tempo uma reunião de algumas das contribuições de seu pensamento para a consolidação de uma episteme dialógica, sensível e criativa, experimentada na pesquisa para a Tese Música e Vida Urbana (OLIVEIRA, 2008) e que em projetos acadêmicos e práticas pedagógicas e de pesquisa. Ana Clara tinha um olhar sensível para o outro. Este gesto não só era experimentado no cotidiano, como constituía parte significativa de sua proposta de teórico-metodológica.

Ana Clara Torres Ribeiro buscava consolidar esta episteme dialógica e sensível no âmbito do LASTRO - Laboratório da Conjuntura Social: Tecnologia e Território e foi em um Encontro Nacional de Geógrafos que conheci uma das pesquisas orientadas por Ana Clara ${ }^{4}$, que evidenciavam estas Cartografias das escutas do Outro, das resistências e das insurgências, tal como citado na epígrafe. Dois depois de conhecer o trabalho do Lastro, foi, sem dúvida, um privilégio ter Ana Clara como orientadora no curso de Doutorado no Instituto de Pesquisa e Planejamento Urbano e Regional. Esta parceria permitiu a busca por um diálogo entre mundos aparentemente distantes: o campo acadêmico e o campo musical, e também de reconhecimento de numerosos outros diálogos e encontros possíveis na cidade, opção metodológica de pesquisa, que esteve direcionada ao reconhecimento da sensibilidade do Outro e as racionalidades alternativas que convivem com a racionalidade hegemônica.

Neste artigo, a proposta é pensarmos o diálogo de Ana Clara com Jean-Paul Sartre (1967), Henri Lefébvre (1974, 1976, 1987, 2001a; 2001b), Milton Santos (1994; 1997; 2007), Michel de Certeau (2003), Carrano (2003) e as contribuições deste diálogo para o pensamento geográfico, principalmente no que se refere à formação do geógrafo pesquisador-professor e à prática docente.

\section{OS SABERES PRÓPRIOS DOS LUGARES E O INCENTIVO AO DIÁLOGO}

O reconhecimento dos diferentes saberes próprios dos lugares e o incentivo ao diálogo colaboram para a consolidação de uma episteme sensível e dialógica, que não só é necessária, como é urgente para pensar a vida social, tal como nos inspira Ribeiro (2004b). Para a autora (RIBEIRO, 2004a), lugar e saber são idéias-conceitos e também idéias-projetos. Segundo a autora, na obra de Milton Santos, tais idéias indicam experiências e expectativas que, desdobradas nos espaços opacos (antagônicos aos espaços luminosos do agir operacional, estratégico e do marketing), propiciam a resistência social (SANTOS, 1994 apud 
RIBEIRO, 2004a). Para a autora, tais noções indicam contextos propícios à descoberta de temas que devem ser incorporados à pesquisa socialmente comprometida, além de orientar a busca do sujeito da transformação e de um modelo cívico que favoreça a real experiência da cidadania.

Tal como Ribeiro (2004a) propõe, algumas idéias e conceitos sinalizam rumos possíveis para a ação social e que correspondem a verdadeiras ferramentas para a elaboração de projetos voltados ao desvendamento de relações sociedade-espaço conduzidas por racionalidades alternativas. Para a autora,

por meio da idéia-conceito de saber manifesta-se a frente de investimentos reflexivos voltada ao diagnóstico dos efeitos nocivos da tecnociência, associada ao esmaecimento da pauta humanista e da produção científica que, abrigada nos códigos do racionalismo ocidental, nega o diálogo com o senso comum. (RIBEIRO, 2004a)

Assim, Ribeiro nos chama atenção para o fato de que "o saber é a força dos lugares, da mesma forma que o lugar é a seiva de diferentes saberes" (RIBEIRO, 2004a:47). Para a autora,

ambas as idéias (conceitos e projetos) correspondem à tenacidade do existir, à insistência do fazer a vida, à riqueza do agir realmente experimentado. São idéias que conduzem, sem separá-los para além do que a ética exige, conhecimento e ação política, e que, ao trazerem concretude à luta por cidadania, obrigam o repensar de relevantes fenômenos sociais.

Tal como propõe Carrano (2003:26) inspirado em Bakhtin, "a complexidade da vida social nas cidades necessita ser compreendida em sua dimensão comunicacional dialógica". Esta dimensão se aplica à análise da cidade polifônica, de que fala Carrano (2003) uma vez que esta abriga múltiplas vozes que se cruzam, relacionando-se por sobreposição e contrastes. Mas o método dialógico se aplica de modo igualmente eficaz à formação do sujeito e à ação coletiva em geral que, para Souza (2004), inclui o planejamento urbano crítico. Concordamos que o ensinamento de Freire (2000) sobre o ato de educar reside em vê-lo não apenas como dialético, mas verdadeiramente como dialógico, isto é, fundado no diálogo (SOUZA, 2004) 5 . O diálogo proposto por Freire tem um sentido político filosófico próximo ao indicado por 
$\overline{\text { Lefebvre (2001a) quando este autor sugere que uma teoria geral da cidade e da sociedade }}$ urbana utilize recursos da ciência e da arte.

Apreender as formas pelas quais a arte nos permite reconhecer apropriações e diferentes racionalidades constitutivas da vida social numa cidade, como fizemos no caso da música do Rio de Janeiro (OLIVEIRA, 2008) é, portanto, uma opção de método que enxerga novas possibilidades para a apreensão das falas daqueles que efetivamente estimulam diálogos sobre (e no) espaço urbano. Alguns sujeitos, em suas ações cotidianas, criam uma forma comunicação sensível que traduz necessidades e desejos, muitas vezes desvalorizados pelos técnicos e teóricos que se negam a ouvir as vozes do homem comum - não especialista em planejamento urbano.

Para Carrano (2003), o cultivo da racionalidade crítica, em conjunto com o refinamento de nossas capacidades éticas e sensíveis, pode representar um efetivo combate aos racionalismos que dificultam a apreensão da multiplicidade da realidade cotidiana, podendo se constituir também como condição para o diálogo com a dinâmica que produz múltiplos processos sociais educativos que se desenvolvem na cidade (CARRANO, 2003). Tal como propõe o autor (CARRANO, 2003), a educação é entendida como um amplo processo social, que não se resume aos cotidianos institucionais de aprendizagem. A arte, por exemplo nos faz sentir, indagar, refletir e, portanto, tem uma dimensão conectada à formação do sujeito e, portanto. Para Carrano (2003), "a autoria é múltipla” e a organização democrática de espaços e tempos das cidades identifica-se com a instauração de práticas educadoras orientadas à produção continuada do humano, segundo as necessidades sociais concretas e as trocas comunicativas que produzem sentidos culturais (CARRANO, 2003).

Em suas aulas, palestras e trocas de idéias, Ana Clara falava da necessidade de se consolidar uma nova episteme para o reconhecimento de toda a complexidade e a diversidade da vida urbana atual; não somente pelo fato da ordem hegemônica não ser uma ordem total, mas também pela limitação do modelo mecanicista de leitura da sociedade. Dizia ainda da necessidade de se ter uma imaginação analítica mais ampla, no que diz respeito a teorias e métodos, para que seja possível realizar uma reflexão crítica e consistente sobre as alternativas existentes à racionalidade dominante.

O diálogo desta socióloga sensível com a teoria crítica do espaço formulada por Milton Santos produziu um acúmulo teórico absolutamente pertinente e estimulante. De acordo com Ribeiro (2004a), assumindo tarefas conceituais associadas à valorização do lugar, 
Milton Santos (1999 apud RIBEIRO, 2004a) reposicionou a categoria território na teoria crítica do espaço, alertando para sua relevância na ação política, por meio da compreensão do território usado. Com base em Milton Santos, vemos que

O território constitui-se numa categoria mediadora, posicionada entre o passado e o presente e, ainda mais, indispensável ao desvendamento dos futuros possíveis. Esta capacidade mediadora emerge no intercâmbio entre gerações e conjunturas. (SANTOS, apud RIBEIRO, 2005c)

Para Santos e Silveira (2001, p. 247), o território, em si mesmo, não constitui uma categoria de análise. Na visão destes autores a categoria de análise é o território usado, vivo. A partir dessa visão, Ribeiro sugere que nossa leitura do território seja

(...)orientada pela compreensão das lutas de apropriação, [de onde] emerge o rico universo de relações que tem origem nos confrontos entre códigos de conduta e, em termos amplos, entre a concepção dominante da ordem social e os numerosos outros ordenamentos das práticas sociais que se opõem e resistem a esta concepção. Desta ótica, instaura-se a possibilidade de compreensão dos confrontos entre interesses, projetos e visões de mundo que constituem a densidade (espessura) da vida social (RIBEIRO, 2005c, p. 95).

Esta propriedade do território possibilita a compreensão de que o espaço pode ser analisado a partir de formas e processos contíguos e/ou em rede, horizontalidades e verticalidades. De modo sintético, com base na reflexão de Santos (1997), as verticalidades asseguram o funcionamento global da sociedade e da economia, pois se formam a partir de atores hegemônicos que controlam as trocas, informações e normas. Já as horizontalidades são construídas a partir das relações entre iguais, gerando formas de solidariedade (SANTOS, 1997).

A valorização da ação do sujeito e do movimento de costura do tecido social, que ocorre simultaneamente ao seu esgarçamento (RIBEIRO, 2006b), é um dos princípios metodológicos adotado nas pesquisas que buscam consolidar esta episteme dialógica e criativa, como aquelas orientadas por Ana Clara Torres Ribeiros. 
Trata-se de buscar consolidar uma outra forma de fazer ciência, capaz de considerar a emoção presente nas falas cotidianas e a sensibilidade do analista na apreensão dos sentidos que orientam a ação do homem comum. Para o pesquisador reconhecer a complexidade do Outro, é preciso reconhecer sua subjetividade, pois o Outro é mais do que aquilo que o pesquisador vê nele, assim como o Outro é mais do que as suas necessidades objetivas. Sartre (1967) busca refletir as relações sujeito-objeto, afirmando que, para compreender o Outro (o objeto), é preciso conhecer a si mesmo (sujeito do conhecimento). O sujeito do conhecimento precisa se interrogar e refletir sobre seus métodos e a formação do analista indica as circunstâncias de elaboração da pesquisa e o ângulo com o qual observa o fenômeno escolhido para a análise (SARTRE, 1967 apud OLIVEIRA, 2008). A escolha do tema, das teorias e os valores que constituem a moral do analista revelam a forma pela qual o sujeito pesquisador desvenda processos.

Permitir uma abordagem mais sensível do (e com) o Outro é uma das principais orientações de método praticadas e deixadas por Ana Clara Torres Ribeiro. Para Sartre (1967, p. 126), "nossa compreensão do Outro não é jamais contemplativa: não é senão um momento de nossa praxis, uma maneira de viver, na luta ou na conivência, a relação concreta e humana que nos une a ele".

Para Freire (2000) a beleza de ser gente está na liberdade de escolher o que fazer diante do Outro; pois, a auto-valorização só é possível quando há o reconhecimento sensível das diferenças e uma aceitação sincera do Outro. Diante dos desafios da sociabilidade, a música ajuda a reconhecer a criatividade, a sensibilidade, a emoção e a intuição na formação do sujeito e, assim, nas identidades sociais.

Para Morin, (2002, p.126), “a liberdade supõe, ao mesmo tempo, a capacidade cerebral ou intelectual de conceber e fazer escolhas, e a possibilidade de operar essas escolhas dentro do meio exterior". Morin (id, p.127), afirma que "é preciso reconhecer que, potencialmente, todo sujeito não é apenas ator, mas autor, capaz de cognição/escolha/decisão".

Torna-se cada vez mais urgente e necessário reconhecer as formas de existência (e de resistência) que caminham no sentido da criatividade, da coletividade e da solidariedade horizontal. Tal como Ribeiro (2005b), acreditamos que "são os que experimentam a escassez que precisam desvendar as múltiplas ações possíveis permitidas pelo espaço herdado e costurar projetos num tecido social esgarçado e precário". Na Tese mencionada anteriormente, sobre música e vida urbana, o sujeito que se afirma como portador de direitos 
revela a existência de uma polifonia urbana, isto é, de uma ação que se propaga como uma outra fala sobre o urbano. O sentido político dessa voz insurgente resulta em territorialidades que ganham visibilidade a partir da música, que detém a capacidade de veicular e expressar novos processos e lutas pela apropriação do espaço urbano.

A opção por privilegiar a insurgência, especialmente do homem lento, permite a consideração da voz do sujeito que tenta resistir às imposições de um modo de vida que já dá sinais de esgotamento. Tal como Ribeiro e Lourenço (2005), entendemos o homem lento, proposto por Milton Santos, como uma síntese político-filosófica do Outro e da sua capacidade de criar o discurso que exprime suas carências e de criar caminhos para sua sobrevivência

Como disse Milton Santos, especialmente em razão das carências, os homens menos velozes criam soluções originais para se conectarem ao fazer social,

Por serem "diferentes", os pobres abrem um debate novo, inédito, às vezes silencioso, à vezes ruidoso, com a população e as coisas já presentes. É assim que eles reavaliam a tecnosfera e a psicosfera, encontrando novo usos e finalidades para objetos e técnicas e também novas articulações práticas e novas normas, na vida social e afetiva (...) É na esfera comunicacional que eles diferentemente das classes ditas superiores, são fortemente ativos (SANTOS, 1997, p. 261).

Assim, a figura do homem lento sintetiza sentidos mais amplos da organização social e da participação política daqueles que, por habitarem as áreas opacas da cidade, são os mais prejudicados pela lógica hegemônica do capital. O homem lento desvenda o espaço enquanto o mundo impõe a adesão à velocidade, ao individualismo, à competitividade e à eficácia. Para Ribeiro (2006b) é indispensável reconhecer táticas e estratégias traçadas pelo homem lento, co-partícipe na concepção de usos do território. Para Santos (1994, 2005), os espaços opacos, orgânicos, permitem que a solidariedade desafie a exclusão produzida pela competitividade. Tal como Ribeiro (2005b, p. 7), acreditamos que "são os que experimentam a escassez que precisam desvendar as múltiplas ações possíveis permitidas pelo espaço herdado e costurar projetos num tecido social esgarçado e precário". 
Para Santos (1997, p.182), "a força própria do lugar vem das ações menos pragmáticas e mais espontâneas, freqüentemente, baseadas em objetos tecnicamente menos modernos e que permitem o exercício da criatividade". A visibilidade conquistada através da música letras, sonoridades plurais, gestos e atitudes - favorece a emergência de um novo imaginário social, mais plural que estimula o encontro das diferenças e o diálogo. As narrativas musicais são discursos e todo discurso constitui-se num reflexo da consciência. Esta, por sua vez, é portadora de um reflexo (destorcido) da realidade (NUN, 1989, p.17).

Por meio da música, reconhecemos trocas solidárias que favorecem o intercâmbio social, contribuindo para o reconhecimento de identidades e diferenças (OLIVEIRA, 2008). Insurgências reconhecidas através da música revelam, ainda, uma vida de relações, resistente e tenaz, que se opõe à abstração exigida pelo capitalismo (RIBEIRO, 2005a).

Para que a criação musical vinda de baixo se realize é preciso que sejam estabelecidas horizontalidades solidárias. Ainda de acordo com Santos (1997, p. 227), “as horizontalidades são tanto o lugar da finalidade imposta de fora, de longe e de cima, quanto o da contrafinalidade localmente gerada". Seriam, simultaneamente, lugar da cegueira e da descoberta, da complacência e da revolta. Assim, a criação musical insurgente pode ser vista como produto desse desconforto criador que alimenta a produção de uma nova consciência (SANTOS, 1997, p. 261).

Tal como também afirma Santos (2007, p. 117), a análise do fenômeno da globalização ficaria incompleta se, após reconhecer os fatores que possibilitaram sua emergência, apenas nos detivéssemos em seus aspectos dominantes, de que resultam tantos inconvenientes para a maior parte da humanidade. Segundo o autor, um certo limite dessa evolução permite reconhecer a emergência de inúmeros sinais de que outros processos surgem paralelamente, autorizando pensar que vivemos uma fase de transição para um novo período histórico, que não encontra-se completamente definido.

As outras possíveis racionalidades trabalhadas por Santos aproximam-se da presente análise quando este autor destaca a força do lugar na construção de contra-racionalidades e de racionalidades paralelas. Essas, por sua vez, levantam-se como realidades alternativas frente à racionalidade dominante e apontam caminhos ao pensamento e à ação (SANTOS, 1997).

Michel de Certeau (2003) diz que, para além da produção racionalizada, expansionista, centralizada, barulhenta e espetacular, existe outra produção astuciosa e dispersa; mas, ao mesmo tempo, insinuante, sutil e quase invisível. Esta última produção não se faz notar 
através dos próprios produtos, mas nas maneiras de empregar os produtos oriundos da ordem econômica dominante. Nesta direção, mais do que exclusivamente o mercado de bens culturais, a referida Tese (OLIVEIRA, 2008) preocupou-se com os modos de operação e esquemas de ação dos agentes -criadores/produtores/usuários/consumidores - que "fabricam" maneiras de agir e comportamentos que traduzem escolhas, gostos e preferências.

Mais do que uma reflexão sobre o mercado de bens culturais, a questão construída pela Tese destaca modos de operação e esquemas de ação de sujeitos criadores/produtores/usuários/consumidores - que "fabricam" maneiras de agir e comportamentos que traduzam atitudes, escolhas e preferências (CERTEAU, 2003, p. 44). Ao confrontar a produção racionalizada, expansionista, centralizada e espetacular, esta outra produção, mais coletiva, colaborativa e horizontal insinua-se de forma sutil e persistente, distanciando-se do consumo massivo e alienado.

Para Certeau (2003), os elementos necessários à concepção de uma teoria das práticas encontram-se na cultura ordinária, sendo relevante enfatizar a "cultura comum e cotidiana enquanto apropriação (reapropriação), considerando consumo ou recepção como uma maneira de praticar” (CERTEAU, 2003, p. 16). Para realizar uma teoria das práticas, é preciso reaprender operações comuns e interrogar práticas supostamente expressivas, apenas, da passividade e da disciplina. Tal como afirma Certeau (2003, p. 41),

Se é verdade que por toda a parte se estende e se precisa a rede de 'vigilância', mais urgente ainda é descobrir como é que uma sociedade inteira não se reduz a ela: que procedimentos populares (também 'minúsculos' e cotidianos) jogam com os mecanismos da disciplina e não se conformam com ela a não ser para alterá-los; enfim, que 'maneiras de fazer' formam a contrapartida, do lado dos consumidores (ou dominados?), dos processos mudos que organizam a ordenação sócio-política (CERTEAU, 2003).

Quando falamos da postura adotada pelo pesquisador, as maneiras de fazer indicam ainda caminhos, escolhas, opções de método. A opção por um método capaz de apreender subjetividade e objetividade relaciona-se à necessidade de uma abordagem dialógica que dê conta dos processos que interferem na forma como o sujeito vive os determinantes objetivos da realidade. 
No caso desta reflexão, interessa-nos, ainda, alcançar as contribuições do pensamento dialógico e sensível para a formação do professor e para a relação ensino-aprendizagem em Geografia.

\section{A FORMAÇÃO DO PESQUISADOR: CONTRIBUIÇÕES DE ANA CLARA TORRES RIBEIRO PARA A FORMAÇÃO EM GEOGRAFIA}

Ana Clara Torres Ribeiro (2005b), em uma reflexão sobre a formação do pesquisador afirma que esta constitui um desafio didático específico, especialmente quando se pretende formar um professor-pesquisador, atento ao exercício da investigação e estimulado a pensar como esta prática investigativa pode alterar a docência e a formação de novas gerações (RIBEIRO, 2005b). Para Ribeiro, a formação para pesquisa exige um aprendizado, sempre difícil, do convívio com a incerteza, com a dúvida, com o desconhecido e com o ainda não realizado. Perguntas, questões e atitudes que conduzem à pesquisa sistemática devem ser estimuladas com base em propostas capazes de ampliar a visão do aluno, sujeito produtor do conhecimento novo ou da interpretação radicalmente nova da vida social e das potencialidades do lugar (RIBEIRO, 2005b). Entretanto, para reconhecer o novo é importante dominar amplamente aquilo que já foi feito (idem) tanto pela ciência como pelos saberes populares, e trabalhar estes conhecimentos com base em uma episteme dialógica e criativa.

A proposta de diálogo entre saberes inclui a compreensão de sua relevância ética e epistemológica. Trata-se de pensar como a pesquisa e o ensino da geografia exigem uma formação de sujeitos sintonizados com o conhecimento profundo dos lugares, com a natureza coletiva e colaborativa dos tempos atuais, e que são ou serão os responsáveis pela proposição de novos saberes. Tal proposta instaura a possibilidade dos estudantes serem sujeitos curiosos, ativos na construção de conhecimentos, que considerem as demandas comunitárias, de modo a favorecer o diálogo permanente e horizontal com as comunidades, seus interesses, saberes, experiências práticas e lutas simbólicas.

Trata-se de pensar um espaço-processo, um espaço socialmente construído, por meio de um olhar sensível para o Outro. Trata-se de uma geografia que reconhece no homem lento (SANTOS, 1997), ordinário (CERTEAU, 2003), o sujeito corporificado (RIBEIRO, 2005c) revelador de uma geografia da existência (RIBEIRO, SILVA \& SCHIPPER, 2011). Tal proposta metodológica encontra inspiração em Milton Santos (SANTOS, 1987, 1997) e Ana Clara Torres Ribeiro (RIBEIRO, 2001, 2004a, 2004b, 2005a e 2005b, 2006a e 2006b) e adota 
uma abordagem capaz de alcançar a subjetividade. Tal como propõe Jean-Paul Sartre, o princípio do conhecimento do mundo não é puramente objetivo, pois o ato do sujeito não se esgota na objetividade do gesto. É também vivido subjetivamente nos projetos do sujeito (SARTRE, 1967).

Buscamos refletir a formação do geógrafo-educador com base num método que fosse capaz de alcançar o sujeito, de reconstruir o sentido de sua ação, as motivações originais e os valores que a orientam, considerando que a ação pode ser objetiva quanto ao seu desenrolar e efeitos, mas é subjetiva quanto às motivações. Para tanto, com base na leitura de Sartre, que propõe que o princípio do conhecimento do mundo não é puramente objetivo (SARTRE, 1967), procuramos abordar a questão a partir da subjetividade, que representa um momento do processo objetivo - de interiorização da exterioridade - considerando, também, a exteriorização da interioridade.

Considerando que cada sujeito, através de sua ação, expressa valores que constituem sua própria existência e que revelam as condições subjetivas da sua experiência social concreta, para Sartre o ser humano constitui-se numa originalidade da existência. Há um nível desta existência que só pode ser compreendido pelo pensamento crítico, através do princípio da liberdade (SARTRE, 1967). O ato do sujeito não se esgota no desenho objetivo do gesto. É também vivido subjetivamente a partir dos projetos do sujeito. O projeto, para Sartre, implica na superação subjetiva da objetividade, pois o subjetivo retém em si o objetivo que nega e que supera em direção de uma nova objetividade; e esta nova objetividade, na sua qualidade de objetivação, exterioriza a interioridade do projeto como subjetividade objetivada (SARTRE, 1967:82). Objetivamente, o sujeito social pode não ter "saída", mas, em algum momento, pode agir de forma inesperada e surpreendente sob a orientação da sua subjetividade. Assim, para alcançar o aluno, futuro geógrafo-educador, sujeito fundamental da construção do conhecimento, não se pode desconsiderar a subjetividade, seja do professor ou do aluno.

A Cartografia da Ação (RIBEIRO, 2001) quando aplicada à formação de professores, pode trazer resultados interessantes, tal como demonstraram Ribeiro, Silva e Schipper (RIBEIRO, SILVA \& SCHIPPER, 2011). A cartografia, em sua dimensão plural e diversa, genericamente nomeada como "novas cartografias sociais", pode ser usada em sala de aula de modo a contribuir para a construção de conceitos geográficos e para que os alunos ampliem sua capacidade de análise crítica e de ação, fundamentais à conquista de direitos de cidadania. 
A proposta de Geografia, Cultura e Cidadania: diálogo de saberes no ensino de Geografia, aprovada pelo MEC/SESu para implantação de um grupo PET-Geografia no campus de Nova Iguaçu da Universidade Federal Rural do Rio de Janeiro em 2010 propõe uma metodologia que valoriza a troca horizontal com as comunidades, seus interesses, experiências práticas e lutas simbólicas. Trata-se de estimular o saber com tais grupos sociais e não o saber sobre eles.

A metodologia aponta para uma educação libertária que pretende colaborar para o fortalecimento das lutas por justiça social. A proposta visa enriquecer o conhecimento teórico produzido academicamente com a multiplicidade de idéias que vêm da experiência vivida nos lugares. Com a proposta de complementar a formação dos estudantes de graduação, o PETGeografia busca intensificar relações entre teoria e prática e evidenciar o papel da educação no incentivo ao diálogo e o papel da geografia no aprendizado da cidadania.

Em "O espaço do cidadão", Milton Santos (1987) afirma que a cidadania se aprende e pode se tornar um estado de espírito enraizado na cultura. Para pensar a cidadania na Geografia é necessário considerar que o cidadão é o indivíduo em um lugar (SANTOS, 1997) e, ainda, que há desigualdades sociais que são, em primeiro lugar, desigualdades territoriais, porque derivam do lugar onde cada qual se encontra. Isto significa que para os pobres, estar excluído dos "processos globais" não é a pior das exclusões, pois tal como alerta Santos (1997), a carência de todos os tipos de consumo, seja ele material ou imaterial, não é a única. Há também a carência de participação política, de direitos básicos, enfim, de cidadania, entendida de forma ampliada. Para Santos (1997): “O valor do indivíduo depende, em larga escala, do lugar onde está”, já que o acesso aos bens e serviços essenciais, públicos e até mesmo privados é tão diferencial e contrastante, que uma grande maioria de brasileiros acaba por ser privada desses bens e serviços (SANTOS, 1997). Por vezes, bens e serviços não existem em áreas de favelas e periferias ou não podem ser alcançados por questão de tempo ou de dinheiro.

Entretanto, os indivíduos se unem horizontalmente, para ampliar suas possibilidades de produção e difusão de produtos e idéias e para superar as barreiras impostas pelas verticalidades - normas egoístas e utilitárias que expressam o ponto de vista dos atores hegemônicos. Para Santos (1997, 2007), as horizontalidades, além das racionalidades típicas de verticalidades que as atravessam, admitem a presença de outras racionalidades, consideradas irracionalidades pelos que desejariam que a racionalidade hegemônica fosse reconhecida como única. 
A racionalidade dominante não impede a coexistência de outras racionalidades, isto é contra-racionalidades que, equivocadamente, e do ponto de vista da racionalidade dominante, são denominadas “irracionalidades” (SANTOS, 2007, p. 115). Há insubordinação frente à racionalidade dominante e freqüentes manifestações contrárias ao pragmatismo na vida cotidiana.

\section{CONSIDERAÇÕES FINAIS}

Trata-se de pensar uma formação que permita que a geografia seja capaz de contribuir para a formação do cidadão e para que este se veja como sujeito produtor do espaço. Nesta perspectiva, o que está sendo proposto é a articulação entre leituras de cunho intersubjetivo e simbólico, com o pensamento crítico que sustenta a teoria crítica do espaço. Entendemos que a formação do cidadão implica e aplica um conhecimento sobre a produção do espaço, que envolve a produção social do espaço e a produção política do espaço, porque "o espaço é política" (LEFEBVRE, 1974 e 1976).

Torna-se cada vez mais urgente e necessário reconhecer as formas de existência (e de resistência) que caminham no sentido da criatividade, da coletividade e da solidariedade horizontal. Tal como nos lembra Ribeiro (2005a), no atual período histórico têm sido fortemente alteradas as relações entre produzir conhecimento e fazer política. Refletindo sobre a importância da obra de Milton Santos para o tema, Ribeiro (2004a) sugere que um novo e transformador diálogo entre ciência e política precisa romper os pactos do poder que sustentam essa ação. A presente proposta sugere ainda o diálogo entre a arte, a ciência e a política, nesta busca por reconhecer contextos que propiciem formas alternativas e sensíveis de construção compartilhadas de conhecimentos sobre a vida urbana.

Como afirma Porto-Gonçalves (2006), novos territórios epistêmicos estão tendo que ser reinventados juntamente com outros territórios de existência material silenciados pela escrita da história. Enfim, são novas formas de significar nosso estar-no-mundo, de grafar a terra, de inventar novas territorialidades, enfim de geo-grafar (PORTO-GONÇALVES, 2006). E essa geografia transformada em ação evidencia aquilo que Santos (2000 apud RIBEIRO, 2004a) falava acerca da existência como produtora de sua própria pedagogia. 


\section{NOTAS}

1 - http://lastroufrj.wordpress.com/2011/12/18/homenagem-a-profa-ana-clara-torres-ribeiro/

2 - Idem.

3 - Ibidem.

4 - Refiro-me ao trabalho "Sentidos da ação e lutas por protagonismo em contextos metropolitanos: fragmentação na periferia do capitalismo", apresentado por Laura Maul no Encontro Nacional de Geógrafos em 2002, onde conheci o trabalho de Ana Clara e do LASTRO. Desde aquele momento senti que aquela seria a interlocução que me faltava para colocar em prática o diálogo entre arte, ciência e política, que tanto desejava.

5- O método dialógico representa uma oposição ao autoritarismo da concepção dominante e tradicional da educação, que Freire chama de educação "bancária", a partir da qual o educador “deposita" conteúdos na cabeça dos educandos, reduzindo-os a um papel passivo. Partindo deste método, o conhecimento é construído a partir da troca e do diálogo e o educando revela seu papel ativo na construção do conhecimento.

\section{REFERÊNCIAS BIBLIOGRÁFICAS}

CARRANO, Paulo. Juventudes e Cidades Educadoras. Petrópolis: Vozes, 2003.

CERTEAU, Michel. A invenção do cotidiano: artes do fazer. Petrópolis, Editora Vozes, $3^{\mathrm{a}}$ edição. $9^{a}$ edição, 2003 [1 $1^{\text {a }}$ edição, 1990]

FREIRE, Paulo. Pedagogia da Autonomia. Rio de Janeiro: Editora Paz e Terra, 2000.

LEFEBVRE, Henri. O direito à cidade. São Paulo: Centauro, 2001a [1969]

A cidade do Capital. Rio de Janeiro. DP\&A, 2001b, $2^{\mathrm{a}}$ edição. . Espacio y Política. Barcelona: Penínsola, 1976

. The Production of Space. Oxford (R.U.) e Cambridge (EUA): Blackwell, 1991 / Paris: Armand Colin, 1974.

. Lógica formal lógica dialética. Rio de Janeiro: Civilização Brasileira, 1987.

MORIN, Edgar. Ciência com consciência. Rio de Janeiro: Bertrand Brasil, 2002. 
NUN, José. La rebelión del coro: estudios sobre la irracionalidad política y el sentido común. Buenos Aires, Ediciones Nueva Visión, 1989.

OLIVEIRA, Anita Loureiro de. Música e Vida Urbana: encontros e confrontos na Cidade do

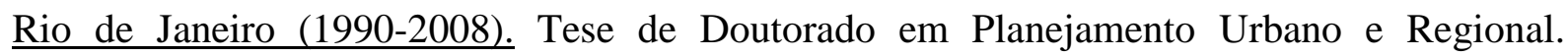
IPPUR/UFRJ. Rio de Janeiro, 2008.

PORTO-GONÇALVES, Carlos Walter. De saberes e de territórios: Diversidade e emancipação a partir da experiência latino-americana GEOgrafia - AnoVIII -N. 16. Niteroi. 2006.

RIBEIRO, Ana Clara Torres. A acumulação primitiva do capital simbólico. In: JEUDY, Henri Pierre; JACQUES, Paola Berenstein (Orgs.). Corpos e Cenários urbanos: territórios urbanos e políticas culturais. Salvador: EDUFBA; PPG-AU/FAUFBA, 2006a. Parte I, cap. 3, p. 39-50.

- Vínculo Social: cartografia da ação em contextos metropolitanos (Segunda fase do projeto: "Cartografia da ação e análise de conjuntura: reivindicações e protestos em metrópoles brasileiras"). Projeto de pesquisa desenvolvido com o apoio do CNPq e da FAPERJ no âmbito do LASTRO - Laboratório da Conjuntura Social: tecnologia e território. $2006 b$

RIBEIRO, Ana Clara Torres e LOURENÇO, Alice. Tipologias da prática: territorialidades insurgentes e racionalidades alternativas. Publicação da Reunião do GT Desenvolvimento Urbano do CLACSO, ocorrida de 13 a 15 de Setembro em Medellín, Colômbia, 2005a.

. Formação do pesquisador: da curiosidade à criação. Revista Tamoios, jan/jun. Ano I, n $12005 b$

Território usado e humanismo concreto: o mercado socialmente necessário. In: Silva, Catia Antonia (et al.) Formas em crise: utopias necessárias. Rio de Janeiro: Arquimedes Edições, 2005c.

. Lugares dos saberes: diálogos abertos. In. BRANDÃO, Maria de A. Milton

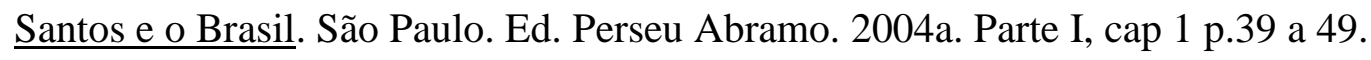

Cartografia da ação e análise de conjuntura: reivindicações e protestos em metrópoles brasileiras. Projeto de pesquisa desenvolvido com o apoio do CNPq e da FAPERJ no âmbito do LASTRO - Laboratório da Conjuntura Social: tecnologia e território, 2004b. 
Por uma cartografia da ação: pequeno ensaio de método. In: Cadernos do IPPUR/

UFRJ. Ano XV. No 2 Ago-Dez, 2001.

RIBEIRO, Ana Clara Torres, SILVA, Catia Antonia da, SCHIPPER, Ivy. Cartografia da Ação e a juventude na cidade: trajetórias de método. In: RIBEIRO, Ana Clara Torres,

RIBEIRO, A. C. T. ; COSTA, Laura Maul de Carvalho; LOURENÇO, Alice ; VILANOVA

NETA, M. A. . Sentidos da ação e lutas por protagonismo em contextos metropolitanos: fragmentação na periferia do capitalismo. 2002.

SANTOS, Milton. Por uma outra globalização: do pensamento único à consciência universal. Rio de Janeiro: Record, 2007.

A natureza do espaço: técnica e tempo, razão e emoção. São Paulo:Editora Hucitec $19972^{a}$ edição.

Técnica, espaço, tempo: globalização e meio técnico-científico informacional. São Paulo, HUCITEC, 1994.

.O espaço do cidadão. São Paulo, Nobel, 1987.

SANTOS, Milton e SILVEIRA, Maria Laura. Brasil: território e sociedade no início do século

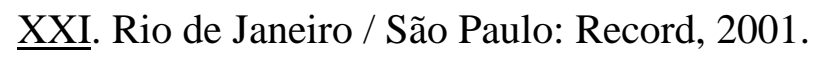

SARTRE, J. P. Questão de método. Tradução de Bento Prado Júnior. São Paulo: Difusão Européia do Livro, 1967.

SOUZA, Marcelo Lopes de. Mudar a cidade: uma introdução ao planejamento e à gestão urbanos. $3^{\text {a }}$ edição. Rio de Janeiro; Bertrand Brasil, 2004. 